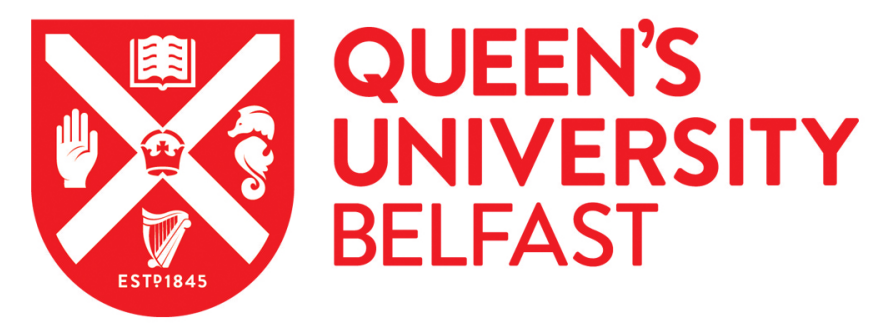

\title{
Commercial sex, clients, and Christian morals: Paying for sex in Ireland
}

Huschke, S., \& Schubotz, D. (2016). Commercial sex, clients, and Christian morals: Paying for sex in Ireland. Sexualities. https://doi.org/10.1177/1363460716638094

\section{Published in:}

Sexualities

\section{Document Version:}

Peer reviewed version

Queen's University Belfast - Research Portal:

Link to publication record in Queen's University Belfast Research Portal

Publisher rights

(C) 2106, The Authors

\section{General rights}

Copyright for the publications made accessible via the Queen's University Belfast Research Portal is retained by the author(s) and / or other copyright owners and it is a condition of accessing these publications that users recognise and abide by the legal requirements associated with these rights.

Take down policy

The Research Portal is Queen's institutional repository that provides access to Queen's research output. Every effort has been made to ensure that content in the Research Portal does not infringe any person's rights, or applicable UK laws. If you discover content in the Research Portal that you believe breaches copyright or violates any law, please contact openaccess@qub.ac.uk. 


\section{Commercial Sex, Clients, and Christian Morals \\ Paying for Sex in Ireland}

\section{Introduction}

In June 2015, the so-called Swedish model (as it was first introduced in Sweden in 1999) - the criminalization of paying for sex - was implemented in Northern Ireland. Following the passing of the law in Northern Ireland, Frances Fitzgerald, Justice Minister in the Republic of Ireland, proposed a change in the Criminal Law (Sexual Offences) Act which would also criminalize clients of sex workers and thereby, as she explained, 'target the predominantly exploitative nature of prostitution' (Press release, 27 November 2014). In both Irish jurisdictions, the sex purchase ban is presented as a measure to reduce human trafficking, following the logic that if paying for sex is criminalized, the demand will be significantly reduced, and if there is less sex work, there will be significantly less trafficking for sexual exploitation.

As elsewhere, Irish supporters of the sex purchase ban commonly present men who pay for sex as careless misogynists or sexual perverts who engage in a 'dirty, seedy business' (Edwin Poots/DUP, NI Assembly debate, 20 October 2014), who 'dictate what they want to do’ (Caitríona Ruane/Sinn Féin, NI Assembly debate, 20 Oct 2014) and to whom 'the women [in the sex industry] were all the same' (Maurice Morrow/DUP, NI Assembly debate, 20 October 2014).. These attitudes and the affiliated legal interventions that target men who pay for sex have become increasingly popular across Europe and North America in the last decade (cf. Sanders and Campbell 2008; Kingston 2009, 2010; Hammond 2015; Huschke et al. 2014: 163-75). Iceland and Norway implemented the sex purchase ban in 2008 and 2009 respectively. However, there has also been significant opposition to the criminalization of clients: it was rejected in Scotland in 2012 and was dropped in England in 2014 before even going to a vote ${ }^{\mathrm{i}}$, demonstrating the cultural differences between Ireland and Britain (cf. Layte et al. 2006; Inglis 2005).

We argue that the Irish debates about commercial sex as well as the experiences of those who pay for sex are shaped and nurtured by the specific local context: Ireland's "highly regulated sexual 
landscape" (Kitchin and Lysaght 2004: 100), based on conservative Christian morals, in which "sex and sexuality are still seen as problems rather than pleasures" (Inglis 2005: 28). In the Republic of Ireland, the continuous influence of the Catholic Church contributes to the permanence of these repressive legal and social norms (Inglis 2005; 1998). In Northern Ireland, "politicians and political lobbyists, who might otherwise divide along Catholic/Protestant or (Irish) nationalist/(British) unionist lines (...), form a united, non-sectarian front in opposing sexual and reproductive rights and services" (Smyth 2006: 664). The dominant sexual culture produced in this context continues to stress chastity, virginity, and modesty and instils a sense of shame and denial about sex (Inglis 2005).

The debate on sex work in Ireland has not just been characterized by this conservative, sexnegative moral discourse, but critically also by a lack of systematic research evidence. The few existing studies on the Irish sex industry focus on sex trafficking (Ward and Wylie 2007) and/or conflate sex work and trafficking by implicitly suggesting that all sex work usually involves exploitation and force, particularly in regard to foreign nationals in the sex industry (Martynowicz et al. 2009, DoJNI 2011; Dudley 2006; Kelleher et al. 2009). Only one study included primary data from a very small sample of those who pay for sex (Yonkova and Keegan 2014), but it did not produce any data on the motivations and subjective experiences of clients across Ireland.

Studies conducted in other parts of the UK (Sanders 2008a, 2008; Liddiard 2014; Earle and Sharp 2007) and in North America (Milrod and Monto 2012; Milrod and Weitzer 2012; Monto and Milrod 2013; Lowman and Atchison 2006), which contradict the dominant narrative of all clients as "exploiters and sexual abusers" (Kingston 2009: 13), were widely ignored in the Irish policy debates. These studies describe a heterogeneous group of men who pay for sex for a variety of different reasons, such as: fulfilling desires to engage in specific sexual acts (such as oral sex); enjoying sex with a number of different people and/or people with specific characteristics (e.g. the 'exotic' woman); preferring commercial sex to conventional relationships or feeling uncomfortable with 'dating'; feeling unsatisfied with one's sex with a current partner; feeling unable to find sexual partners outside of commercial sex (for example due to disability); and enjoying the thrill of the clandestine encounter with a sex worker. Researchers have also stressed that for some clients, the social and emotional side 
of the encounter with a sex worker constitutes a main reason to pay for sexual services, particularly in the growing indoor sex work sector (Earle and Sharp 2007, cf. Sanders 2008; Milrod and Weitzer 2012; Rivers-Moore 2012; Liddiard 2014).

Although the heterogeneity of men who pay for sex and their reasons to do so appear to be similar across different local contexts in Western Europe and North America, we posit that particularly in face of the current wave of end-the-demand policy proposals - thorough studies on clients are still much needed in order to provide research evidence that critically challenges popular myths and over-simplified stereotypes. In addition to adding our Irish case study to this growing literature, our analysis contributes to a debate about the repressive sexual cultures in both Northern Ireland and the Republic of Ireland and the schism between dominant moral discourses and the lived realities of people (cf. Inglis 1998, 2005; Inglis and MacKeogh 2010; Kitchin and Lysaght 2004; Smyth 2006; Duggan 2010; Fegan and Rebouche 2003).

\section{Methodology}

A mixed methods approach was utilized in the study, consisting of online self-completion surveys and face-to-face interviews of sex workers and clients, data scraping ${ }^{\mathrm{ii}}$ to assess the online profiles of sex workers, as well as interviews with service providers and local councils. Data was collected between May and August 2014.

In total, 446 clients completed the online survey. It included questions on demographics as well as clients' experiences of paying for sex - including the age they first engaged in commercial sex, frequency; sectors of the industry accessed; and their motivations ${ }^{\mathrm{iii}}$. The ten face-to-face interviews were semi-structured in nature and designed to complement the survey data in order to gather more indepth insights into the experiences of clients, for example their relationships and typical encounters with sex workers and their views on how paying for sex affected their lives.

All possible efforts were made in the short available time period for this study to recruit respondents from all areas of sex work, including street-based sex work. However, the vast majority of clients who took part in the study were men who pay for sexual services of indoor sex workers who 
advertise via the main Irish and British websites, usually referred to as 'escorts'. Information about the study and a link to the online survey was posted on these websites ${ }^{\text {iv }}$ or emailed directly to those who advertise on these sites. This apparent over-representation of clients of indoor sex workers (as opposed to clients of street-based sex workers) does in fact reflect the growing significance of indoor sex work, particularly online-based 'escort' services, across Ireland (Huschke et al. 2014: 57).

Like all opportunistic sampling frames, our recruitment strategy has weaknesses, and we cannot claim statistical representativeness. We had considered the inclusion of survey questions on sex work in the sexual health section of the annual Northern Ireland Health survey - a representative household survey. However, this idea was abandoned as not feasible due to the subject's sensitivity. It is no coincidence that Northern Ireland is the only part of the UK excluded from the National Survey of Sexual Attitudes and Lifestyles (NATSAL). Considering the time constraint and resources available, we captured a large number and multifaceted range of clients, including clients from minority ethnic groups, with diverse motives, attitudes and experiences. Although we may have missed some data from more informal forms of sex work, we are content that we in principle captured the changing face of the increasingly mobile and internet-based Irish sex industry. Furthermore, all data was triangulated with other data sources, most importantly, with sex workers' survey responses and indepth interviews with nineteen sex workers. The results presented in this paper are backed up by research evidence from our extensive engagement with a diverse group of sex workers (cf. Huschke et al. 2014).

The quantitative survey data was analyzed using SPSS. The qualitative data (i.e. interview transcripts and replies to open-ended questions in the surveys) were fed into NVivo and coded using both inductive (i.e. open/in-vivo coding) and deductive coding strategies (i.e. codes based on the research questions and preliminary research). Qualitative and quantitative results were cross-checked by assessment from two or more data sources, thereby allowing us to verify results. The case examples and quotes included in this paper were selected because they represent the diversity of clients' biographic backgrounds, motivations and experiences while at the same time highlighting general findings (resulting from the study as a whole) and providing typical examples. 


\section{Results}

\section{Diversity of clients}

Almost all of our respondents were male (97\%), with only two percent being female, and one percent identifying as 'trans'. Based on our survey data and interviews with sex workers and service providers, we ascertain that this is generally reflective of the client base across Ireland. Thus, in this paper, we focus on the experiences and motives of male clients.

Nearly two thirds of clients (64\%) were between 31 and 50 years of age: fourteen percent were between 22 and 30 years of age, and 21 percent 51-74 years of age. Very small proportions of clients $(<1 \%)$ were under 22 or over 75 years of age. Most respondents lived in the Republic of Ireland (64\%), whilst 11 percent lived in Northern Ireland and nine percent in other parts of the UK. A relatively high proportion of respondents $(16 \%)$ did not state where they lived, perhaps in order to protect their anonymity. The majority of respondents lived in large cities. Nearly two thirds (63\%) of respondents said they were Irish nationals, followed by 14 percent who said they were British. Two percent said they were 'Northern Irish'. Other nationalities included Indian, Australian, US-American, Romanian, French and German, which is both evidence for the important role mobility plays in regard to commercial sex, but also the growing multi-ethnic composition of Irish society.

Four in ten respondents (42\%) said they were single. Combined with separated/divorced and widowed respondents, over half (52\%) of respondents were not in a relationship. Over half of respondents $(58 \%)$ had an undergraduate qualification or above. Fifty-nine percent of respondents were employed, whilst a further twenty-five percent were self-employed. Five percent said they were retired. A very small proportion of respondents were unemployed or unable to work $(6 \%)$ or were students (2\%). Among the respondents were farmers, doctors, civil servants, care workers, bank clerks, accountants, electricians and company directors. Over one quarter of respondents reported a gross annual income of $£ 50,000$ or above for 2013 with almost three quarters of respondents reporting an income of at least $£ 20,000$ annually. 
Overall, the demographic data demonstrates the diversity of clients; a point emphasized by sex workers who took part in our study, who commonly stated that there is no 'typical' client. Instead, men who pay for sex work in a wide range of professions, they include single as well as married men, fathers as well as men living alone, younger as well as older men. At the same time, the sample consists predominantly of relatively wealthy, well-educated males. This finding is not surprising considering the economic costs of commercial sex, particularly in the internet-based indoor sector. ${ }^{\mathrm{V}}$ These results confirm the findings from the studies undertaken by Groom and Nandwani (2006) and Sanders (2008a) in the UK and Milrod and Monto (2012) in the US.

\section{Paying for sex}

The vast majority of clients in our sample pay for the services of female sex workers (85\%). The majority of respondents (58\%) said that they would see different sex workers. Only five percent said that they would always see the same sex worker. However, nearly one third of respondents said that they tried to see the same one, but would see others if this were not possible. Survey respondents commented that they had 'a small number of favourites, but would sometimes choose to meet new people too' or that they 'prefer[red] to see only one or two escorts on a regular basis as it allows friendship and trust to develop.' This result clearly shows that a significant number of clients aim to establish some form of social relationship with sex workers.

In regard to the frequency with which clients purchase sexual services, we found that over half of respondents paid for sexual services no more than a few times a year (Figure 1).

\section{Figure 1: Frequency with which respondents have purchased sexual services (\%)}




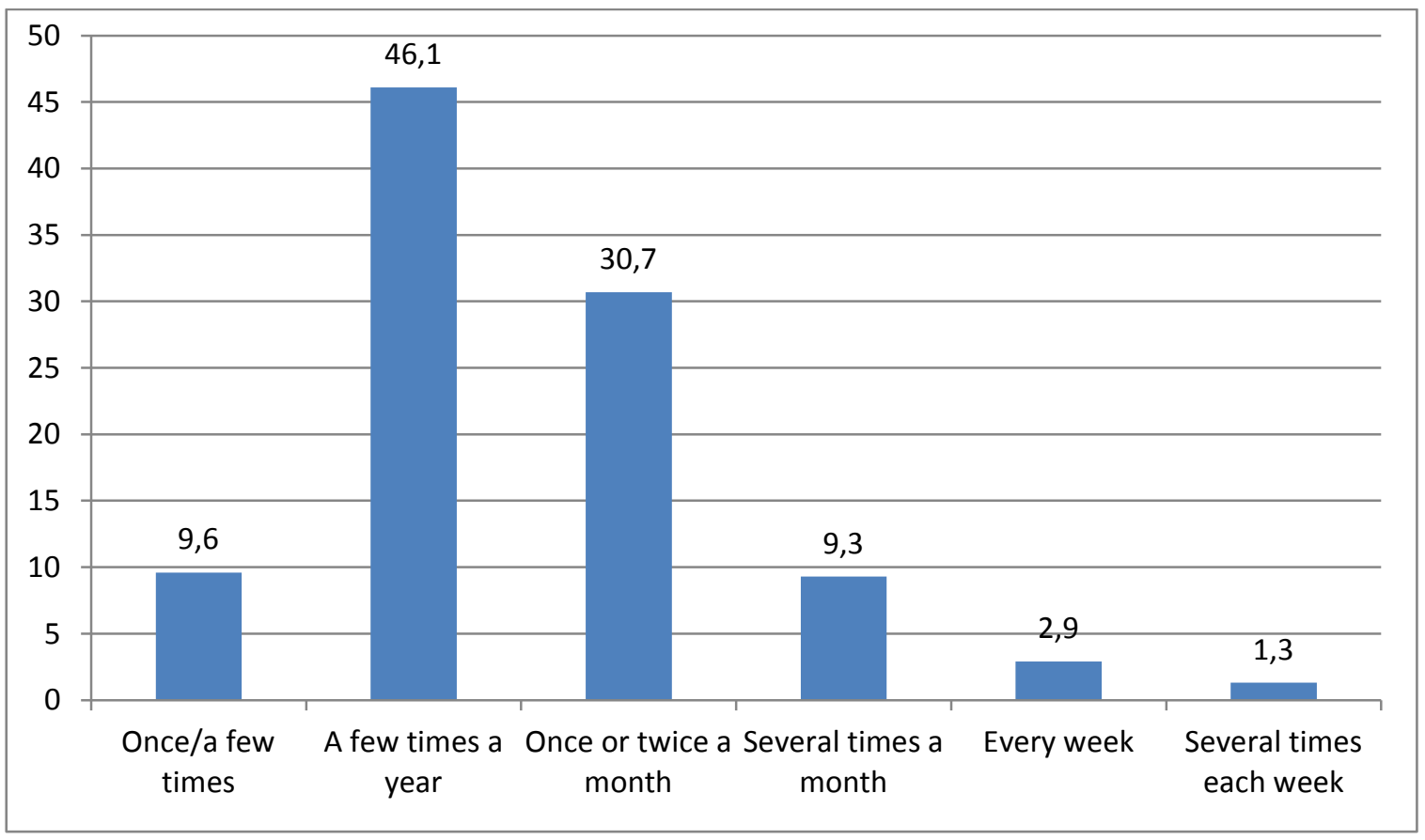

Respondents were asked what they liked (Table 1) and disliked (Table 2) about buying sexual services. The most commonly stated positive aspects of paying for sex referred to (the client's) sexual pleasure and being able to explore new and different sexual practices.

Table 1: What respondents like about buying sex. Rank-ordered (\%)

\begin{tabular}{|l|c|}
\hline & $\%$ \\
\hline I enjoy having sex with different people & 47 \\
It allows me to try things I haven't tried before & 40 \\
I like that there are no emotional strings attached & 41 \\
It allows me to do things I couldn't do with a partner & 38 \\
It is the only way I can get sex & 28 \\
The secrecy of it gives me a thrill & 25 \\
It makes me feel more confident about myself and my body & 21 \\
It's good for my self-esteem & 19
\end{tabular}




\begin{tabular}{|l|c|} 
I just did it out of curiosity & 16 \\
It's quick and easy: I don't have time for other sexual relationships & 16 \\
It is the only way I can get sexual satisfaction & 9 \\
I don't feel ready for other sexual relationships & 8 \\
None of the above & $<1$ \\
\hline
\end{tabular}

Some survey respondents gave additional comments in which they explained further what they liked about buying sex or why they did it. Their statements referred to opportunism, lack of self-confidence and shyness around women, medical conditions, or sexual preferences which make it difficult to find a suitable partner. Some clients also reported that they had sex with sex workers because they were living in 'sexless' or 'loveless' marriages with no physical contact, or because their relationship with their partners had broken down. Some respondents stated that sex with a sex worker is the easier, but also a 'more honest' and safer option than affairs or one-night-stands.

In regard to negative aspects of paying for sexual services, the two most common responses in the survey both focused on the stigma attached to paying for sex, and concerns about being 'found out' (Table 2).

Table 2: What respondents dislike about buying sex. Rank-ordered (\%)

\begin{tabular}{|l|c|}
\hline & $\%$ \\
\hline I feel like I have to hide what I do, I don't like that. & 41 \\
I worry that my friends and family will find out about it & 39 \\
I feel like I have to lie about what I do, I don't like that. & 31 \\
I am worried about the health risks. & 25 \\
I feel that I spend too much money on it. & 25 \\
\hline
\end{tabular}




\begin{tabular}{|l|c|} 
I miss the emotional connection. & 21 \\
I didn't get good value for money. & 12 \\
I don't like the settings in which it takes place. & 10 \\
It makes me ashamed. & 10 \\
I was hoping it would lead to more than just sex. & 5 \\
It damages my confidence. & 3 \\
\hline
\end{tabular}

In the free comments, survey respondents often expressed concerns about the well-being and safety of the sex workers. One client stated, for example: 'I am concerned that sex work will damage the sex worker's chances of a stable relationship in the future' and another one worried that the 'ladies can be exposed to any type of guy at any time; it can be a dangerous job'.

Some survey respondents alluded to issues of guilt and the stigma attached to commercial sex. One respondent complained about the 'false morality and fake piety' attached to sexual relationships in Irish society, and another respondent expressed how he felt 'annoyed' at himself after visiting sex workers. Mirroring these responses, clients who were interviewed face-to-face elaborated on the theme of growing up/living in a morally conservative society. Dan, a divorced man in his late 40s who identifies as atheist, commented:

\footnotetext{
When I was younger, this place [Northern Ireland] was just, I would say oppressive, [that's] probably the best word for it. (...) There is on both sides, the Protestant and the Catholic side, a sort of a control system, as regards sexuality, it's a way of controlling people and telling them what to do and keeping them within the flock.
}

Jonathan, another divorcee in his 40s, acknowledged that certain things had changed, for example the attitude towards premarital sex, but that the stigma attached to commercial sex prevailed. He said:

\footnotetext{
We are slowly coming out of the Dark Ages. It is going to take a long time admittedly. Religion is very much in use as a means of control especially in Northern Ireland.
} 
And Philip, a man in his 30s, commented on his upbringing and how his attitudes towards sex changed over time:

Well, up until I was about thirty-five (...) it was a case of 'no sex before marriage'. I was a good little Catholic boy. Horny $99 \%$ of the time because of it, but that's the choice I made because of the way I was raised. (...) And then, well, it got to that point where it was just a case of: Why? Really, is having sex a sin?

\section{Clients' views on criminalization}

As this study was conducted to inform the NI Assembly discussion on the criminalization of clients, respondents were asked under which circumstances they would stop paying for sexual services. The two most likely reasons given by respondents were if they were in a relationship (35\%) or if they could have sex without paying for it (27\%). Some survey respondents also stated that they would stop having sex with a sex worker if they 'found out the girls are trafficked or forced'. None of the respondents said they had ever personally witnessed trafficking, and only two percent said that someone else had

told them that they had been, at some point (not currently), been trafficked into the sex industry. ${ }^{\text {vi }}$ The comments received in the survey suggest that some clients ask sex workers 'if they were under any sort of coercion, before having sex' and only have sex once they have been assured 'that they are doing this voluntarily'. Of course it is debatable whether or not any sex worker is in fact in the position to say so, but our results (in line with the comments regarding clients' concerns about sex workers presented above) clearly contradict the stereotype that clients are generally neither interested in the well-being of the sex worker nor in consensual sex.

Respondents were also asked what they would do if it was made illegal to pay for sexual services. The results suggest that criminalizing paying for sex would be a very ineffective policy measure. Only seven percent of survey respondents said they would stop paying for sex altogether if it was illegal whilst fifteen percent would simply pay for sex elsewhere. The most likely responses given by clients were that they would only see sex workers that they trusted $(42 \%)$ or simply would be more careful (38\%). Thirteen percent of respondents said they would not do anything differently. 
When asked how the criminalization of clients of sex workers would affect the sex workers themselves, only four percent of clients thought that sex workers would actually stop selling sex. Crucially, 57 percent thought that a sex purchase ban would make things less safe for sex workers, and in additional comments clients expressed the view that it would drive sex work further underground and create more precarious and risky working conditions, a view shared by the majority of sex workers who took part in the study (cf. Huschke et al. 2014: 178-80). These results, alongside our findings from client interviews as well as the interviews and survey with sex workers, are substantiated by previous studies (Hammond 2015; Sanders 2008) that show that many clients are mindful and considerate in relation to working conditions of sex workers.

\section{Case studies}

In this section we present a number of case studies of clients who were interviewed for this study. The cases exemplify the different rationales for clients to buy sexual services and thereby provide a more in-depth understanding of the client base and the complexity of their lived experiences.

Case study 1. Nick ${ }^{\mathrm{vii}}$ lives in the Republic of Ireland and regularly travels across the border to Northern Ireland for business. He is in his early 40s, single, and owns a farm. His first encounter with a sex worker was a birthday present a friend bought for him. Since then, he has been visiting sex workers regularly about once a month. In the interview, Nick explains that 'paying for sex is easier than going out and meeting someone to have sex with'. Nick feels that sex with escorts is a different kind of sex, which allows him to experiment:

\footnotetext{
If you just meet someone for the first time, or even if you meet someone for a month, well, how do I introduce fetish into our relationship? You know, there's an awful lot of hoops and rings that you've got to dance through (...). And I guess that's what escorts for me mean, they list their services, if there are things there you'd like to try, it's there.
}

During the interview, it became apparent that Nick was generally skeptical about the social institution of marriage: 
To be honest: if I'm in a relationship, if I got married, all of a sudden she controls the purse strings, because if anything ever happens - through my fault or her fault, or through nobody's fault, the marriage is up, I pay a price for that, a financial price, for that for the rest of my life. (...) So for me, escorts provide that compartmentalized situation where I can enjoy curious sex or I can experiment, non-judgmentally, and it's compartmentalized. And, you know, that's kind of why the core reason of why I do it.

At the same time, Nick explained that many of his encounters with sex workers involve more than just sex:

\begin{abstract}
About 40 percent of the time I've stayed well after hours, be it twenty minutes, half an hour, an hour after the scheduled appointment, chatting, talking, effectively in the groove, you know. Talking about anything from YouTube to how they got into the industry or what're they going to do once they leave. Just really casual; and I have to admit as a personal thing, part of me will enjoy that almost more than the sex itself, that human contact.
\end{abstract}

Case study 2. Roger, who lives in Northern Ireland, is a self-employed man in his late 50s who says he has been happily married for 35 years and has three grown-up children. In his interview he disclosed that his marital sex life got worse and worse until eventually, he and his wife did not have sex anymore. When he asked his wife to see a councilor about this she refused. Roger explained:

If I had a good, active sex life at home, I definitely wouldn't be going to any escorts, but you know, my wife just doesn't want to - she just shuns the whole thing, really, you know. [...] We're still very happily married, you know, we still go out and socialize quite a bit, but it's just, you know, when it comes to the sex - I suppose I sort of gave up.

For Roger, seeing sex workers relieves his 'sexual frustration', as he puts it. Similar to Nick, the social interaction and emotional connection with the sex worker is as important as the sex:

Maybe about half the time that I'm with these girls I spend talking to them, maybe, you know, as opposed to... maybe I'm looking for company as well, you know. [...] Half the time I want to be cuddled, and hugged, intimately. [...] It's someone you can open up to and tell everything about really, and some of the escorts, I count them as very good friends of mine now, you know.

Roger views paying for sexual services as a better and less complicated option than having an affair and he hopes that this prevents a confrontation with his wife and, thereby, saves his marriage. 
Case study 3. Bob is a British man in his 50s who lives in the Republic of Ireland. He is single and works in a hospital. Bob identifies as a heterosexual cross-dresser. Bob still keeps his gender identity a secret from his family, friends and colleagues. He has had relationships before where he was open about cross-dressing, but these did not last. He explains that being a male cross-dresser who is sexually interested in women renders his romantic life significantly more difficult. Seeing escorts that accept him as a heterosexual cross-dresser is the solution for Bob, but not a permanent one, as he hopes to enter a romantic relationship with a woman eventually:

I have my needs, I need sex; it's the only way I can do it. [...] I am feeling special, feeling relieved, you know. But I would love to be with a proper girl, that's all I want in life. If that happens then I stop seeing them.

Thus, for Bob, paying for sex is a way of finding sexual satisfaction while being able to express his identity as a cross-dresser: 'I go there dressed up, [...] they accept me for what I am.' Being asked about how his Christian upbringing comes into play when he pays for sex, Bob said:

I'm rebelling. It feels like I'm sticking two fingers up to the Catholic Church. (...) I felt like going back to school and then pulling down my pants and saying: I'm going to hell, Sister Delores, look!

Case study 4. Paul is in his 60s and a retired professional from Belfast. A few years ago he separated from his wife, with whom he has several children. Paul started paying for sex with sex workers after he experienced a period of severe depression and soul-searching when he tried to make sense of who he had been. Seeing sex workers helped him discover his own sexuality and come to terms with his emotional crisis: 'It makes me feel a lot better and helps the depression.' In the interview, he talks about Northern Ireland as a 'repressed and inhibited' place where 'the normal social construct [is] that people - man and woman - should be married and have children [and] anything else is perversion'. After his relationship breakdown, he unsuccessfully tried to find another partner through dating sites, which he feels was a waste of time:

A lot of the women said they were looking for, quote, romance, unquote. I don't know whether that was correct or not, but... that just seemed to be a palaver, and going to see a prostitute seemed in many ways a much more honest thing to do. I want something, she wants money; we are both mutually happy - the end. 
In the interview Paul stated that he found many of the sex workers he had met interesting to talk to and that he was impressed by their life stories and personalities. Contradictory to the cultural myths he grew up with, he found that sex workers were:

...real people. They are not the - well at least the ones I have met - not the ferocious heroin-addicts, dripping disease, that you read about in so many descriptions, they seem to be perfectly nice people. (...) I discovered an awful lot of the things that I might have been told are myths and rubbish.

\section{Discussion}

\section{Hidden sexual desires and sex-less relationships}

The survey responses and interviews clearly show that satisfying sexual needs constitutes a main reason for men to pay for sex, as could be expected. However, our results also reveal that the social circumstances, sexual desires and motives of clients are much more complex than the public discourse on commercial sex across Ireland would have us believe, and are shaped by the dominance of a repressive sexual culture and conservative Christian moral values.

Our data show that the majority of clients buy sex when heterosexual monogamous long-term relationships, which constitute the social and sexual norm across Ireland, either break down or do not meet their sexual and/or social and emotional needs. Some study participants expressed the view that commercial sexual encounters allowed them to try new sexual practices, as Nick's and Paul's cases show. In the online indoor sex industry the interactions between sex workers and clients usually include direct communication about sexual acts before (and during) the encounter. For someone like Bob, who identifies as a heterosexual cross-dresser and feels that he does not fit into mainstream dating cultures, but also for someone like Paul, who feels that he only learned to explore and acknowledge his sexual needs and desires in his 60s, this openness towards a diversity of sexual preferences and frank communication about sex represents an important aspect of clients' relationships with sex workers. This factor - a common feature of commercial sex - can be assumed to be particularly relevant in the context of a sexually repressed 'local moral world' (Kleinman 1999) such 
as Ireland, where 'the attempt to fulfil sexual desires and pleasures can still be an awkward, shameful and embarrassing experience' (Inglis 2005: 29).

Our data show that marriage remains an influential and powerful social institution in Ireland. Paradoxically, our results suggest that this hetero-normative social expectation to lead a monogamous heterosexual life within the confines of marriage is another reason why some men engage in commercial sex. Many of our research participants considered their marriages to be an important part of their lives and were not prepared to leave their partners and children. The fact that divorce rates are significantly lower in Northern Ireland and the Republic of Ireland compared to other parts of the UK and mainland Europe suggests that divorce is not considered a morally and socially acceptable option by parts of the population (NISRA 2013; Office for National Statistics 2014). At the same time, there is no socially expected template to deal with unsatisfactory sexual relationships within marriage, and as Brooks-Gordon and Gelsthorpe have pointed out, 'to go outside a monogamous "relationship" and purchase intimacy or sexual practices violates contemporary ideals and cultural customs' (2003: 442). Our data show that most married clients would prefer having satisfying sex in a loving relationship with their long-term partner, and raise the question: what are the acceptable options for someone who wants to keep his or her family life, but who also desires to have his or her sexual needs met?

\section{More than just sex}

While commercial sex is arguably primarily about the client's sexual needs, our data clearly show that it is more than that. Commercial sex involves social interactions and emotional aspects, which play an important role for many clients - a fact that is ignored when men who pay for sex are presented as ruthless sexual perverts who 'treat women and young girls as a commodity that they can buy for their sexual gratification' (Paul Givan/DUP, NI Assembly debate, 20 Oct 2014). All of our interviewees and many of the survey respondents explained that talking, joking, hanging out and 'having a bit of craic' $^{\text {viii }}$ often constitute an important element of the encounter, particularly with sex workers they had seen before. In recent years, the so-called 'Girlfriend Experience' (GFE) has received some scholarly interest, exploring those encounters with sex workers that include social interactions such as dining 
together and emotional performances such as cuddling and kissing (Rivers-Moore 2012; Bernstein 2007; Sanders 2008a; Milrod and Weitzer 2012). While it has been argued that emotional intimacy has long been an aspect of interactions between clients and (particularly, but not exclusively) indoor sex workers, it is now more explicitly advertised and has - under the label of GFE - become an important feature of online escort services (Weitzer 2009: 227).

Bernstein coined the term 'bounded authenticity' to describe how clients seek a 'real and reciprocal erotic connection, but precisely a limited one' (2001: 402), limited to the paid encounter and - in theory - not extending beyond that. Some clients explicitly stated that they did not feel the need to be in a conventional relationship and preferred encounters with sex workers because there were (usually) no emotional strings attached. In our survey, 38 percent of respondents offered this as one of their reasons to pay for sex - one of the most common responses. For example, Roger, who is married, felt that paying for sex was less emotionally problematic than having an affair, and Nick, a single man, stressed that paying for sex allows him to stay clear of the financial responsibility and emotional commitment that he feels comes with conventional relationships. He felt that seeing sex workers allowed him to avoid marriage, which he perceived as financially and emotionally undesirable.

In regard to these somewhat contradictory motivations and perspectives of clients, Sanders (2008b) argues that the difference lies in the patterns of commercial sex that clients engage in: on one hand, those who usually see different sex workers are more commonly motivated by seeking sexual diversity and non-committed relationships. On the other hand, clients who become 'regulars', that is, who see only one (or only a few) sex workers over longer periods of time usually seek emotional, social and sexual interactions that are similar to those of non-commercial sexual relationships, including talking about 'personal stuff', buying gifts, establishing emotional closeness (often described in terms of a 'friendship' by both regular clients and sex workers in our study), learning about the sexual preferences of the sex worker and seeking mutual sexual satisfaction. In some cases, client-sex worker-relationships develop into something less 'bounded' and may even turn into conventional relationships or lasting friendships (cf. Milrod and Weitzer 2012). Thus, sex workers sometimes 
provide a kind of emotional support and social interaction that clients do not experience (regularly) in their marriages or other social relationships. ${ }^{\text {ix }}$

\section{Caring about the sex workers' well-being?}

As our data show, the desire to find sexual pleasure does not automatically mean that men who pay for sex are simply looking for a receptive, passive female body for sexual release, as maintained by supporters of the sex purchase ban like Northern Irish MLA Caitríona Ruane (Sinn Féin) who declared that '[women's] bodies are being touched, grabbed and penetrated again and again, usually on a daily basis, having different men dictate what they want to do' (NI Assembly debate, 20 Oct 2014). In fact, many clients regard it as important that the interaction they have is pleasant for the sex worker, too, for example by giving massages or performing oral sex on her/him (cf. Lever and Dolnick 2010). This is in line with Milrod and Monto's finding that clients of online escorts seek sexual encounters with a woman who 'really likes sex' and 'acts very uninhibited and horny' (2012: 801). The men interviewed for this study explained that giving pleasure to a person who enjoys sex increases their own sexual pleasure as well, and in some cases, they juxtaposed this experience with a lack of mutual sexual pleasure in long-term relationships with their partners. ${ }^{\mathrm{x}}$

More generally, our data reveal that most clients in the internet-based indoor sector take the well-being of the sex worker into consideration: they worry about the possible negative effects of selling sex and state that they would not pay for sex with somebody who appears coerced or forced. This constitutes a stark contradiction to the image painted in the public discourse on both sides of the Irish border, where clients are described as sexual predators that do not care whether the person they pay for sex is an independent sex worker or a victim of trafficking. As with all survey data, a social desirability bias means that the expressed attitudes do not always translate into practice, and we cannot be certain whether those who expressed concern for the well-being of the sex workers in the survey would actually walk away from an encounter with someone who appears distressed and/or might be forced or coerced. However, the experiences and views of the sex workers we captured in our study 
would support the conclusion that the majority of clients respect sex workers' boundaries (e.g. in terms of included and excluded sexual practices, hygiene, payment) and are not looking for (or accepting of) non-consensual sex. Nevertheless, most indoor sex workers have encountered disrespectful clients at some point (e.g. clients who use derogative language or disregard sexual boundaries), and many longterm sex workers have occasionally experienced violence from clients (cf. Huschke et al. 2014: chapter 6). Despite of this, our findings do not support the stereotype that the majority of men who pay for sex do not care about the well-being of the sex workers, frequently treat them without respect, or abuse them.

Rather than leading to less violence against women, we argue that the stigmatizing, moralistic discourse around sex work in Ireland may actually contribute to disrespectful and abusive practices in the sex industry: when all sex workers are perceived as helpless victims of trafficking and/or the sex industry, there is very little room to discuss the different working conditions sex workers find themselves in, the appropriate and inappropriate behaviors of clients, the various ways in which sex workers can (and do) render their working lives safer, and the promotion of harm-reduction practices and support services that would allow more sex workers to protect themselves from violent and abusive clients. Our research shows that in the absence of an open-minded public debate about the actual needs and experiences of sex workers, information offered on the main escort websites and in online forums play an important role in establishing 'codes of conduct' for clients (cf. Milrod and Monto 2012: 796; Hammond 2015). For example, the most commonly used website in our study (EscortIreland) displays an 'Eejit's $\mathrm{s}^{\mathrm{xi}}$ Guide to Escorts' that encourages clients to familiarize themselves with the specific offers, boundaries and rules of each sex worker before setting up a meeting and stresses that disrespectful behavior including for example poor hygiene and showing up late or drunk is inacceptable. Clients who took part in our study described how, over time, they had learned to communicate and interact respectfully with sex workers. In addition to information shared in online forums, their interactions and conversations with sex workers helped to deconstruct stereotypical negative images, exemplified in Paul's comment that sex workers are nothing like what the public discourse had made him believe, but indeed are 'real people (...), perfectly nice people'. 


\section{Conclusion}

In this paper we have shown that motives of men who pay for sex and their attitudes towards commercial sex relate to and reflect the local moral world that they live in, shaped by conservative Christian values and a lack of sex-positive public attitudes that embrace sexual diversity. We found that clients are a heterogeneous group with diverse reasons to pay for sex. Our research adds to the growing number of studies that provide insights that challenge the dominant public images of clients, which are mainly based on moral judgments and stereotypes of those involved in commercial sex rather than robust research evidence (cf. Campbell and Storr 2001: 98). While many sex workers experience violence and disrespectful behavior at some point during their time in the sex industry, our results clearly show that this is not the norm, and that the majority of clients in the online-based indoor sector (i.e. the 'escort industry') comply with rules set by sex workers and are not looking for nonconsensual sex or use physical violence.

Furthermore, our data clearly shows that a sex purchase ban is unlikely to achieve its objective. Due to the stigma attached to commercial sex, which has been perpetuated by the morally charged policy debates on both sides of the Irish border, paying for sex already 'felt' illegal for many clients before the new law was implemented in Northern Ireland. This perception, alongside strong personal motivations to pay for sexual services renders it unlikely that the sex purchase ban will fundamentally transform clients' attitudes and practices. Instead, as we have shown elsewhere, criminalizing clients is likely to contribute to worse working conditions for sex workers and likely make vulnerable people who currently work in the sex industry even more vulnerable to labor exploitation, violence and abuse (cf. Huschke et al. 2014: chapter 10; cf. Brooks-Gordon 2010).

Thus, we conclude that the recent public debates on commercial sex in Ireland and the implementation of the so-called Swedish model in Northern Ireland constitute a 'moral crusade' (Weitzer 2006) against sex work, which is perceived as transgressing sex-negative, conservative Christian moralities. By employing negative stereotypes and ignoring the existing research evidence 
on men who pay for sex, promoters of the sex purchase ban have missed an opportunity to allow an open and less prejudiced debate about people's sexual desires and the social norms that shape them.

\section{References}

Barry K (1995) The Prostitution of Sexuality: The Global Exploitation of Women. New York: NYU Press.

Bernstein E (2001) The meaning of the purchase: Desire, demand and the commerce of sex. Ethnography 2(3): 389-420.

Bernstein E (2007) Temporarily Yours. Intimacy, Authenticity, and the Commerce of Sex. Chicago_ University of Chicago Press.

Brooks-Gordon B (2010) Bellwether citizens: the regulation of male clients of sex workers. Journal of Law and Society 37(1): 145-70.

Brooks-Gordon, B and Gelsthorpe L (2003) Prostitutes' clients, Ken Livingstone and a new Trojan horse. The Howard Journal 42(5): 437-451.

Campbell R and Storr M (2001) Challenging the kerb crawler rehabilitation programme. Feminist Review 67(Spring): 94-108.

DoJNI (Department of Justice Northern Ireland) (2011) Research paper investigating the issues for women in Northern Ireland involved in prostitution and exploring best practice elsewhere.

Available at: http://www.dojni.gov.uk/index/publications/final_research_paper__women_in_northern_ireland_involved_in_prostitution.pdf (accessed 7 April 2013).

Dudley R (2006) Crossing Borders: Preliminary Research on Human Trafficking in Northern Ireland. Belfast: Women's Aid Federation Northern Ireland.

Duggan M (2010) The politics of Pride: representing relegated sexual identities in Northern Ireland. Northern Ireland Legal Quarterly 61(2): 163-78.

Earle S and Sharp K (2007) Sex in Cyberspace. Men who Pay for Sex. Farnham: Ashgate. 
Eurostat (2014). Marriage and divorce statistics. Available at: http://ec.europa.eu/eurostat/statisticsexplained/index.php/Marriage_and_divorce_statistics (accessed 20 February 2015).

Fegan E and R Rebouche (2003) Northern Ireland's abortion law: The morality of silence and censure of agency. Feminist Legal Studies 11: 221-254.

Groom T M and Nandwani R (2006) Characteristics of men who pay for sex: a UK sexual health clinic survey. Sexually Transmitted Infections 82(5): 364-367.

Hammond N (2015) Men who pay for sex and the sex work movement? Client responses to stigma and increased regulation of commercial sex policy. Social Policy \& Society 14(1): 93-102.

Huschke S, Shirlow P, Schubotz D, Ward E, Probst U and Ní Dhónaill C (2014) Research into Prostitution in Northern Ireland. Available at:

http://www.dojni.gov.uk/index/publications/publication-categories/pubs-criminaljustice/independent-research-into-prostitution-in-northern-ireland.htm (accessed 14 December 2014).

Inglis T (1998) Lessons in Irish Sexuality. Dublin: University College Dublin Press.

Inglis T (2005) Origins and legacies of Irish prudery: Sexuality and social control in modern Ireland. Eire-Ireland 40 (3\&4): 9-37.

Inglis T and MacKeogh C (2012) The double bind: Women, honour and sexuality in contemporary Ireland. Media Culture and Society 34 (1): 68-82.

Jeffreys S (2008) The Industrial Vagina: The Political Economy of the Global Sex Trade. London: Routledge.

Kelleher P, O’Connor M, Kelleher C and Pillinger J (2009) Globalisation, sex trafficking and prostitution. The experiences of migrant women in Ireland. Dublin: Immigrant Council of Ireland. Available at: http://www.immigrantcouncil.ie/images/stories/Trafficking_Report_FULL_LENGTH_FINAL.pdf (accessed 7 December 2014)

Kingston S (2009) Demonising desire: men who buy sex and prostitution policy in the UK. Research for Sex Work, 11: 13-14. Available at: http://www.nswp.org/resource/research-sex- 
work-11-englishfrench (accessed 19 October 2015)

Kingston S (2010) Intend to criminalize: men who buy sex and prostitution policy in the UK. In: Hardy K, Kingston S and Sanders T (eds) New Sociologies of Sex Work. Farnham: Ashgate, pp. 23-38.

Kitchin R and Lysaght K (2004) Sexual citizenship in Belfast, Northern Ireland. Gender, Place and Culture 11(1): 83-103.

Kleinman A (1999) Moral experience and ethical reflection. Can ethnography reconcile them? A quandary for 'the new bioethics'. Daedalus 128 (4): 69-97.

Layte R, McGee H, Quail A, Rundle K, Cousins G, Donnelly C, Mulcahy R and Conroy R (2006) The Irish Study of Sexual Health and Relationships. Dublin: The Crisis Pregnancy Agency and the Department of Health and Children.

Lever J and Dolnick D (2010) Call girls and street prostitutes: Selling sex and intimacy. In: Weitzer R (ed) Sex for Sale: Prostitution, Pornography, and the Sex Industry. New York: Routledge, pp. 187203.

Liddiard K (2014) 'I never felt like she was just doing it for the money': Disabled men's intimate (gendered) realities of purchasing sexual pleasure and intimacy. Sexualities 17(7): 837-855. Martynowicz A, Toucas S and Caughey A (2009) The nature and extent of human trafficking in Northern Ireland: A scoping study. Belfast: Institute for Conflict Research. Available at: http://conflictresearch.org.uk/reports/migration/The_Nature_and_Extent_of_Human_Trafficking_in _Northern_Ireland_LR.pdf (accessed 3 December 2014).

Milrod C and Monto M (2012) The hobbyist and the girlfriend experience: Behaviors and preferences of male customers of internet sexual service providers. Deviant Behavior 33(10): 792-810.

Milrod C and Weitzer R (2012) The intimacy prism: Emotion management among the clients of escorts. Men and Masculinities 15(5): 447-467.

Monto M (2010) Prostitutes' Customers: Motives and Misconceptions. In: Weitzer R (ed) Sex for Sale: Prostitution, Pornography, and the Sex Industry. New York: Routledge, pp. 233-254. 
Monto M and Milrod C (2013) Ordinary or peculiar men? Comparing the customers of prostitutes with a nationally representative sample of men. International Journal of Offender Therapy and Comparative Criminology 58(7): 802-820.

NISRA (Northern Ireland Statistics and Research Agency) (2013) Marriages, Divorces and Civil Partnerships in Northern Ireland 2012. Available at: http://www.nisra.gov.uk/archive/demography/publications/marriages_divorces/MDCP2012.pdf (accessed 20 February 2015).

Office for National Statistics (2014) Divorces in England and Wales, 2012. Available at: http://www.ons.gov.uk/ons/dcp171778_351693.pdf (accessed 20 February 2015).

Rivers-Moore M (2012) Almighty gringos: Masculinity and value in sex tourism. Sexualities 15(7): $850-870$.

Sanders T (2008a [2012]) Paying for Pleasure. Men Who Buy Sex. $2^{\text {nd }}$ edition. London: Routledge.

Sanders T (2008b) Male sexual scripts: Intimacy, sexuality and pleasure in the purchase of commercial sex. Sociology 42(3): 400-417.

Sanders T and Campbell R (2008) Why hate men who pay for sex? Investigating the shift to tackling demand and calls to criminalise paying for sex. In: Munro V (eds) Demanding Sex? Critical Reflections on the Supply/Demand Dynamic in Prostitution. Surrey: Ashgate, pp. 163-180.

Skilbrei, M and Holmström, C (2013) The 'Nordic model' of prostitution law is a myth. The Conversation (16 December 2013). Available at: http://theconversation.com/the-nordic-model-ofprostitution-law-is-a-myth-21351 (accessed 19 October 2015).

Smyth, L (2006) The cultural politics of sexuality and reproduction in Northern Ireland. Sociology 40(4): 663-680.

Ward E and Wylie G (2007) The Nature and Extent of Trafficking of Women into Ireland for the Purposes of Sexual Exploitation 2000 - 2006: A report from findings. SSRS Research Papers and Reports, No. 39, SSRC, NUI Galway. 
Ward H, Mercer C H, Wellings K, Fenton K, Erens B, Copas A, Johnson A M (2005) Who pays for sex? An analysis of the increasing prevalence of female commercial sex contacts among men in Britain. Sexually Transmitted Diseases 81: 467-571.

Weitzer R (2006) Moral crusade against prostitution. Society 43(3): 33-38.

Weitzer R (2009) Sociology of sex work. Annual Review of Sociology 35: 213-234.

Yonkova, N and Keegan E (2014) Stop Traffick! Tackling demand for sexual services of trafficked women and girls. Dublin: Immigrant Council of Ireland. Available at: http://www.immigrantcouncil.ie/images/stories/documents/STOP_TRAFFICK_-_full_report.pdf (accessed 8 December 2014).

Zimmerman Y (2012) Other Dreams of Freedom. Religion, Sex, and Human Trafficking. Oxford: Oxford University Press. 


\section{Endnotes}

${ }^{\mathrm{i}}$ Similarly, the sex purchase ban was rejected by the French Senate in 2015 and in 1999 Denmark opted for legalization instead (cf. Skilbrei and Holmström 2013).

ii The term 'data scraping' refers to the computer-generated retrieval of data from websites.

iii The full list of 45 questions is included in the final research report, see Huschke et al. 2014.

${ }^{\text {iv }}$ Escort Ireland, Irish Independent Escorts, Adultwork, Vivastreet, Backpage and Craigslist.

${ }^{v}$ In the internet-based indoor sector, prices are generally based on time rather than the specific service provided. The price for a 30 min-service ranges from $£ 30$ to $£ 150$. In comparison, prices in the Northern Irish street-based sector were generally said to be around $£ 50$ for full sex, $£ 30$ for oral sex and $£ 20$ for 'hand relief' (cf. Huschke et al. 2014: 55-8).

${ }^{\text {vi }}$ This reflects our findings in regard to the trajectories of sex workers who said that they had been trafficked at an earlier stage of their lives: most commonly, sex workers reported that they were exploited by someone else when they first entered the sex industry, but had since then moved on and started working independently. In most cases, their experience of exploitation referred to the working conditions (e.g. having to pay more 'fees' than originally agreed, having to work more hours or having to work in dirty apartments), and much less commonly to being forced to sell sex against their will (cf. Huschke et al. 2014: 133-5).

${ }^{\text {vii }}$ All names are pseudonyms.

viii Craic (Irish) means fun, entertainment, banter.

${ }^{\text {ix }}$ Our survey and interviews with sex workers show that this aspect of service provision is not necessarily a 'fake performance': many sex workers described their relationships with regular clients as resembling friendships and stated that they enjoyed the time spent together. However, more in-depth research is necessary to draw out the complexities of sex worker-client relationships in the Irish context.

${ }^{\mathrm{x}}$ It is beyond the merit of this paper to discuss in more detail to what extent this 'mutual pleasure' merely exists in the client's imagination, and whether it perhaps increases the pressure that the sex worker, the 'sexual and emotional labourer' (Sanders 2008a: 99), feels in regard to her 'performance' (cf. Milrod and Monto 2012, and Plumridge et al. 1997 for reflections on this). However, our survey and interview data validates that a significant percentage of indoor escorts occasionally or regularly experience sexual pleasure with clients.

${ }^{x i}$ Eejit is Irish slang for idiot. 